Article

\title{
Quantitative Analysis of Dynamic Behaviours of Rural Areas at Provincial Level Using Public Data of Gross Domestic Product
}

\author{
Yi Chen ${ }^{1,2}$, Guangfeng Zhang ${ }^{3,4}$, Yiyang Li $^{5}$, Yi Ding ${ }^{6}$, Bin Zheng ${ }^{7, *}$ and Qiang Miao ${ }^{1}$ \\ ${ }^{1}$ School of Mechatronics Engineering, University of Electronic Science and Technology of China, \\ Chengdu, 611731, China; E-Mails: leo.chen.yi@live.co.uk (C.Y.); mqiang@uestc.edu.cn (M.Q.) \\ ${ }^{2}$ School of Engineering and Built Environment, Glasgow Caledonian University, Glasgow,
} G4 0BA, UK

${ }^{3}$ GREQAM, School of Economics, Aix-Marseille University, Marseille, 13236, France; E-Mail: guangfeng.f.zhang@gmail.com (Z.G-F.)

${ }^{4}$ Department of Economics, Adam Smith Business School, University of Glasgow, Glasgow, G12 8RT, UK

${ }^{5}$ Department of Mechanical and Automation Engineering, The Chinese University of Hong Kong, ShaTin, New Territories, Hong Kong; E-Mail: yli@mae.cuhk.edu.hk (L.Y.)

${ }^{6}$ Department of Electrical Engineering, Technical University of Denmark, 2800 Kgs. Lyngby, Denmark; E-Mail: yding@elektro.dtu.dk (D.Y.)

${ }^{7}$ Chongqing Institute of Green and Intelligent Technology, Chinese Academy of Sciences, Chongqing 401120, China

* Author to whom correspondence should be addressed; E-Mail:zhengbin@cigit.ac.cn; Tel.: +86-23-6306-1485; Fax: +86-23-6306-1366.

Received: 7 November 2012; in revised form: 4 December 2012 / Accepted: 7 December 2012 / Published: 20 December 2012

\begin{abstract}
A spatial approach that incorporates three economic components and one environmental factor has been developed to evaluate the dynamic behaviours of the rural areas at a provincial level. An artificial fish swarm algorithm with variable population size (AFSAVP) is proposed for the spatial problem. A functional region affecting index $(\Theta)$ is employed as a fitness function for the AFSAVP driven optimisation, in which a gross domestic product (GDP) based method is utilised to estimate the $\mathrm{CO}_{2}$ emission of all provinces. A simulation for the administrative provinces of China has been implemented, and the results have shown that the modelling method based on GDP data can assess the spatial dynamic behaviours and can be taken as an operational tool for the policy planners.
\end{abstract}


Keywords: spatial analysis; functional region; dynamic behaviours; social behaviours; carbon dioxide emission; public data; gross domestic product; swarm algorithm; artificial fish

\section{Introduction}

During the past two decades, China's rapid economic growth has been making China become one of the largest contributors to the global economy and natural environment issues [1]. Combining with China's large population, rapid urbanisation, increasing household wealth demands and local economic redisbtribution, unbalanced pressure has deployed on regional development and caused low efficient environmental recycle. Issues of the local impact of various air pollutants on the regional economic development, such as carbon monoxide $(\mathrm{CO})$, nitrogen oxides $\left(\mathrm{NO}_{x}\right)$, sulphur dioxide $\left(\mathrm{SO}_{2}\right)$, have been extensively discussed.

The global warming is one of the most serious environmental issues that human currently confronts. The mechanism of global warming has not yet been fully understood. However, it has been considered closely related to the emission of the anthropogenic greenhouse gases, such as carbon dioxide $\left(\mathrm{CO}_{2}\right)$ and methane $\left(\mathrm{CH}_{4}\right)$. These issues has attracted researchers' extensive interest, and in reality various countermeasures, such as technological development, abatement policies based on economic mechanisms and international negotiations, have been discussed and partially applied into practices [2,3].

As it has been widely accepted, $\mathrm{CO}_{2}$ emission is connected with the human activities mainly through the consumption of fossil fuel type energy, for example the operation of a fossil fuel power station. To evaluate the dynamic behaviours of the regional areas coupled with energy consumption and $\mathrm{CO}_{2}$ emissions, a few interdisciplinary studies have been conducted. Berling-wolff and Wu outlined the historical development of urban growth models, which indicated the different disciplines and diverse theories could be brought together to hybrid the newly developed models including fuzzy logic theory and neural network theory [4]. Nejadkoorki et al. proposed a model for the road traffic $\mathrm{CO}_{2}$ emissions of an urban area with three components [5]. Weiss et al. presented a bottom-up model for the non-energy use of fossil fuels and its $\mathrm{CO}_{2}$ emissions [6]. Bala discussed rural energy supply projections and assessed the contributions to global warming. Dynamic system models have provided an overall energy balance analysis [7]. Generally speaking, these study integrated interdisciplinary factors and in particular used the interaction between economic activities and surrounding environmental factors.

In recent years, computational intelligence methods, such as genetic algorithms (GA), swarm algorithms, fuzzy logic methods and artificial neural network (ANN), have been widely used in empirical applications [8-22].

The artificial fish swarm algorithm (AFSA) [23] is one of the swarm algorithms, which is inspired by the social behaviours of the fish school in searching, swarming and following. A schooling fish can response quickly to the changes in the direction and speed of their neighbours, and the information of their behaviours can be passed to others and help them move from one configuration to another almost as one unit. By borrowing this intelligence of the social behaviours, the AFSA is parallel and independent 
to the initial values, and able to achieve a global optimum. In this paper, an AFSA method with the variable of population size (AFSAVP) is proposed, which is applied to the intelligent approach for a spatial analysis that incorporates three economic components and one environmental factor of carbon dioxide emission.

\section{Variable Population Size Fish Swarm Algorithm}

Inspired by the swarm intelligence of the fish schooling behaviours, the AFSA is an artificial intelligent algorithm that firstly simulates the behaviour of an individual artificial fish (AF) and then constructs an AF schooling. Each AF searches its own local optimal solution and passes information to its self-organized system, and finally achieves the global optimal solution.

The AFSAVP provides a one-variable AF population $P$. As stated in Equation (1), the AF school population $P$ is made up of two sub-schools: the replaceable school $P_{R}$ and the non-replaceable school $P_{N}$. Equation (2) gives $P_{R}$ at generation $t$, which is calculated by its own size plus the off-size $\Delta P_{R}$ at generation $t-1$. As stated in Equation (3), the off-size replaceable population is proportional to the size of $P_{R}$, where $\lambda$ is a reproduction rate set by users.

$$
\begin{gathered}
P(t)=P_{R}(t)+P_{N}(t) \\
P_{R}(t)=P_{R}(t-1)+\Delta P_{R}(t-1) \\
\Delta P_{R}(t)=\lambda P(t)
\end{gathered}
$$

The AFSAVP work-flow is given in Figure 2, which is similar to the basic AFSA [23,24]. The AFSAVP includes five steps of operations: (1) behaviour selection; (2) searching behaviour; (3) swarming behaviour; (4) following behaviour and (5) bulletin. A "max-generation" is the trial number of an AF school searching for food under a given initial condition, which is one of the widely used criteria for the AFSAVP simulation termination.

Behaviour Selection: in the AFSAVP, the behaviour selection step takes searching behaviour as the default or initial behaviour for each AF. According to the food density, the number of companion and the visual conditions, the AF school select their behaviours, which includes searching behaviour, following behaviour and swarming behaviour.

Searching Behaviour: for a certain AF individual $k, S_{k}=\left\{s_{1}, \ldots, s_{M}\right\}$ is its finite state set, there is $M$ states that an AF can perform in. Within the AF's visual field, if the current state of this AF is $S_{i}$ and the next state is $S_{j}$, the AF moves from $S_{i}$ to $S_{j}$ randomly and check the state updating conditions as stated in Equations (4) and (5). As demonstrated in Figure 1, $r_{i j}=\left\|S_{j}-S_{i}\right\|$ is the distance between the $i^{t h}$ and $j^{t h}$ individual AF. $\digamma=f(S)$ is the food density for this AF, where $\digamma$ is the fitness function. $\delta$ is the iterate step, $v$ is the AF visual constant.

$$
S_{i+1}= \begin{cases}S_{i}+R A N D \cdot \delta \cdot \frac{S_{j}-S_{i}}{\left\|S_{j}-S_{i}\right\|} & \text { if } \digamma_{j}>\digamma_{i} \\ S_{i}+R A N D \cdot \delta & \text { otherwise }\end{cases}
$$




$$
S_{j}=S_{i}+R A N D \cdot v
$$

Figure 1. The state distance between the $i^{\text {th }}$ and $j^{\text {th }}$ individual.

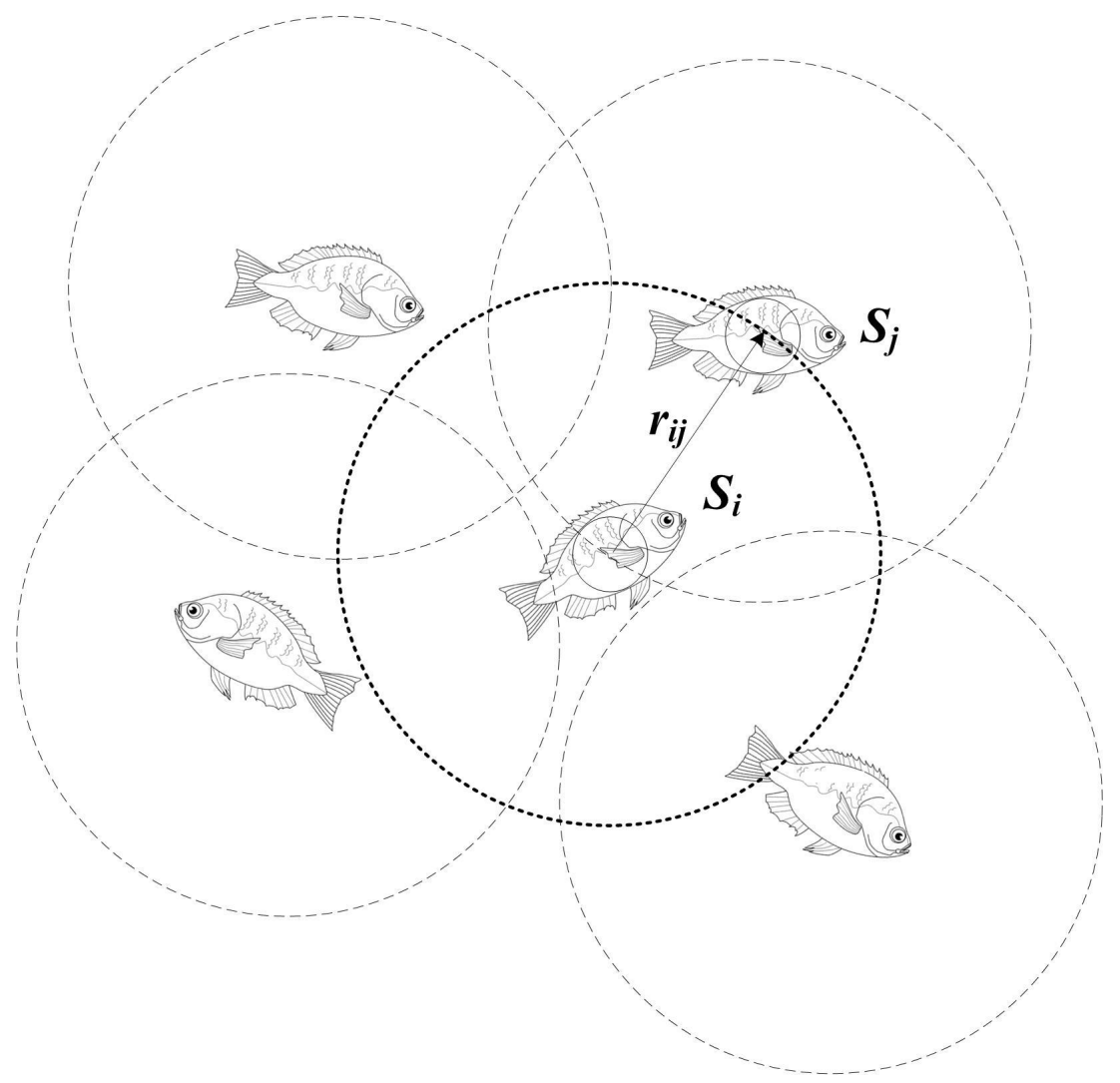

Swarming Behaviour: suppose the number of this AF's neighbours is $\alpha$, the central state is $S_{c}$, the food density is $\digamma_{c}=f\left(S_{c}\right)$ and $\eta$ is the crowd factor. Within its visual field $\left(r_{i j}<v\right)$, if the $\digamma_{c} / \alpha>\eta \digamma_{i}$ and $\eta \geq 1$, the AF implements the central state driven step; otherwise, when the $\digamma_{c} / \alpha \leq \eta \digamma_{i}$ or $\eta=1$, the AF will go on with the searching behaviour, as expressed in Equation (6).

$$
S_{i+1}=\left\{\begin{array}{lll}
S_{i}+R A N D \cdot \delta \cdot \frac{S_{c}-S_{i}}{\left\|S_{c}-S_{i}\right\|} & \text { if } \frac{\digamma_{c}}{\alpha}>\eta \digamma_{i} \text { and } \eta \geq 1 \\
\text { equation(4) } & \frac{\digamma_{c}}{\alpha} \leq \eta \digamma_{i} \quad \text { or } \quad \eta=0
\end{array}\right.
$$

Following Behaviour: when the AF's companions reach "max" state $S_{\max }$ with the number $\alpha$ within the neighbourhood, the food density reaches $\digamma_{\max }$ at the mean time. As stated in Equation (7), with the same conditions as Equation (6), the AF updates its state in highest food density area; otherwise, the AF will go on with the searching behaviour, as expressed in Equation (6).

$$
S_{i+1}=\left\{\begin{array}{lll}
S_{i}+R A N D \cdot \delta \cdot \frac{S_{\max }-S_{i}}{\left\|S_{\max }-S_{i}\right\|} & \text { if } \frac{\digamma_{\max }}{\alpha}>\eta \digamma_{i} \text { and } \eta \geq 1 \\
\text { equation(4) } & \frac{\digamma_{\max }}{\alpha} \leq \eta \digamma_{i} \quad \text { or } \quad \eta=0
\end{array}\right.
$$


Bulletin: the bulletin operation is a step to compare each AF's current state $S_{i}$ with the historical state data, the bulletin data will be replaced and updated only when the current state is better than the last one, as described by Equation (8).

$$
S_{j+1}= \begin{cases}S_{j} & \text { if } \digamma_{j}>\digamma_{i} \\ S_{i} & \text { otherwise }\end{cases}
$$

Figure 2. The variable population size fish swarm algorithm workflow.

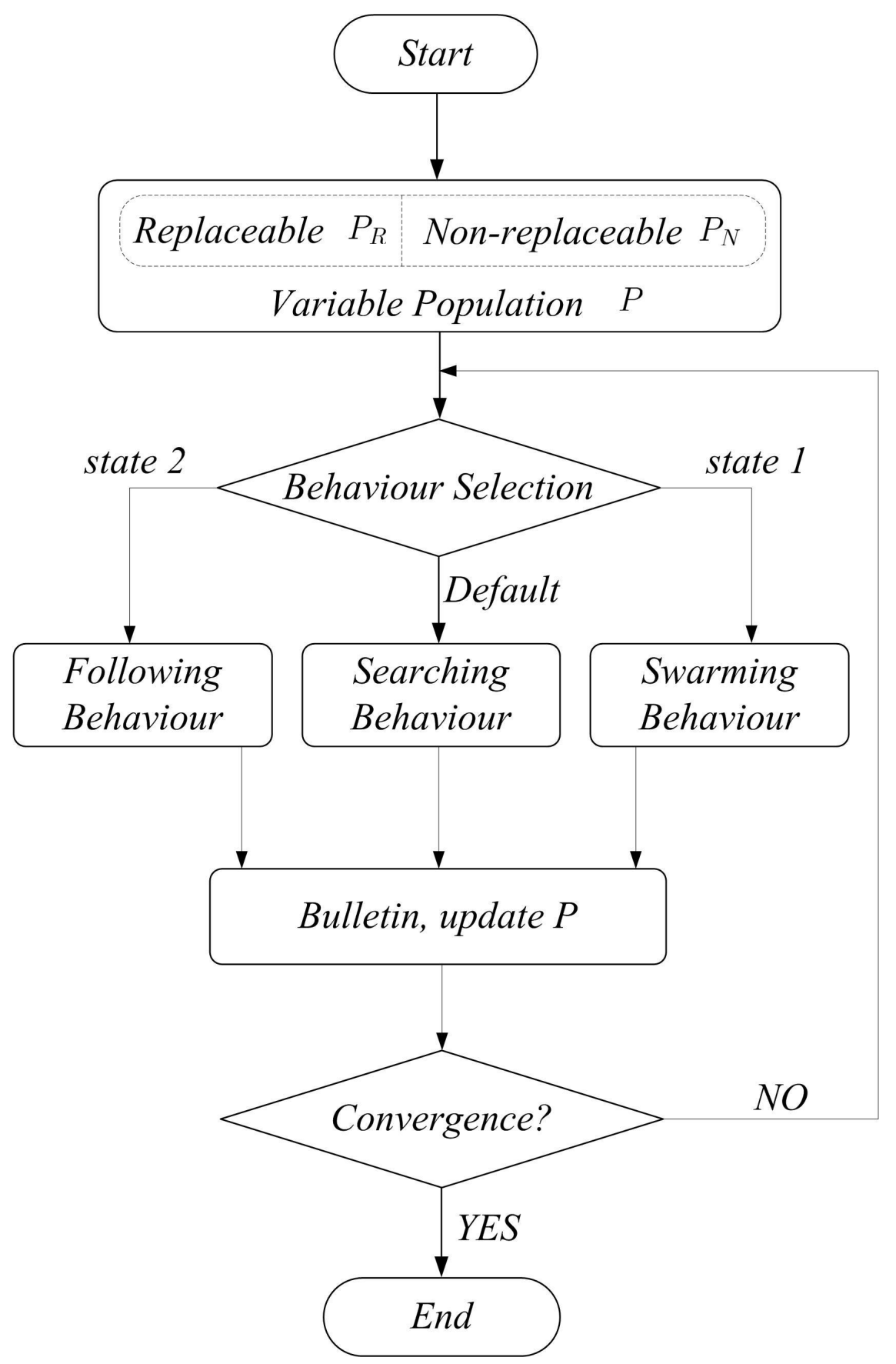




\section{Quantitative Analysis Framework}

A framework of this quantitative analysis of dynamic behaviours is given in Figure 3, which summarises five steps for the overall process. Step 1 is to introduce the data source, which includes statistical yearbooks, independent reports and other big data sources. Step 2 is data management, which is to capture, clean, store, manage, and process the data within an applicable time scale. Step 3 is the data analytics, in which the gross domestic product (GDP) is used to estimate $\mathrm{CO}_{2}$ emission and the AFSAVP method is utilised to optimise the parameters of the multi-state dynamic behaviours model. Step 4 is to visualise the outputs and present the results. In step 5, the result is employed for advising policy makers and data enabled applications.

Figure 3. Framework of quantitative analysis of dynamic behaviours.

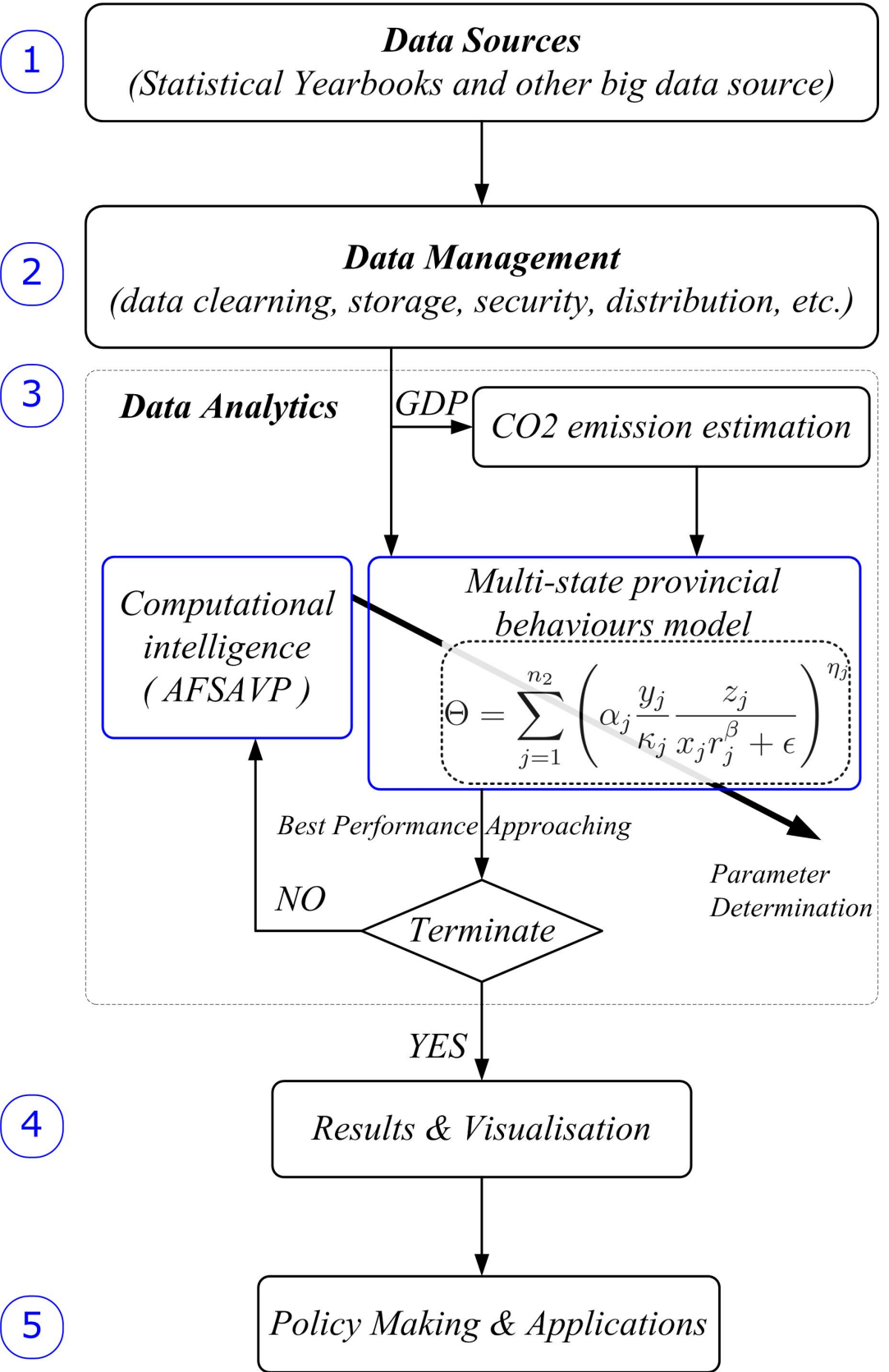


According to "Revised 1996 IPCC Guidelines: Reference Manual, Volume 3" [25], the estimation of the $\mathrm{CO}_{2}$ emissions, which is related to the productive activity for the rural area of each province, requires three major data for each of fuel type: the heat conversion factors (HCF), the carbon emission factor (CEF) and the fraction of carbon oxidised (FOC) in each sector. As listed in Table 1, the three types of data are provided by different data sources [26,27] for the rural areas with local impacts, which includes three aspects: liquid (row A), solid (row B) and gaseous (row C).

Table 1. Heat conversion factor, carbon emission factor, fraction of carbon oxidised of various fossil fuels [25-27].

\begin{tabular}{|c|c|c|c|c|}
\hline$i$ & Fuel & $\begin{array}{c}\text { Conversion Factor } \\
\qquad \alpha_{i}\left(T J / 10^{3} t\right)\end{array}$ & $\begin{array}{c}\text { Emission Factor } \\
\qquad \beta_{i}(t C / T J)\end{array}$ & $\begin{array}{l}\text { Fraction of Carbon Oxidised } \\
\qquad \gamma_{i}\end{array}$ \\
\hline \multirow[t]{3}{*}{$\overline{\mathbf{0}}$} & TCE & 29.27 & 24.74 & 0.90 \\
\hline & (A) Liquid & & & \\
\hline & Primary Fuel: & & & \\
\hline \multirow[t]{2}{*}{1} & Crude Oil & 42.62 & 20.00 & 0.98 \\
\hline & Secondary Fuel: & & & \\
\hline 2 & Gasoline & 44.80 & 18.90 & 0.98 \\
\hline 3 & Kerosene & 44.67 & 19.55 & 0.98 \\
\hline 4 & Diesel Oil & 43.33 & 20.20 & 0.98 \\
\hline 5 & Residual Fuel Oil & 40.19 & 21.10 & 0.98 \\
\hline 6 & LPG & 47.31 & 17.20 & 0.98 \\
\hline 7 & Naphtha & 45.01 & 20.00 & 0.80 \\
\hline 8 & Bitumen & 40.19 & 22.00 & 1.00 \\
\hline 9 & Lubricants & 40.19 & 20.00 & 0.50 \\
\hline \multirow[t]{3}{*}{10} & Other oil & 40.19 & 20.00 & 0.98 \\
\hline & (B) Solid & & & \\
\hline & Primary Fuel: & & & \\
\hline \multirow[t]{2}{*}{11} & $\overline{\text { Raw Coal }}$ & 20.52 & 24.74 & 0.90 \\
\hline & Secondary Fuel: & & & \\
\hline 12 & Clean Coal & 20.52 & 24.74 & 0.90 \\
\hline 13 & Washed Coal & 20.52 & 24.74 & 0.90 \\
\hline 14 & House Coal & 20.52 & 24.74 & 0.90 \\
\hline 15 & Coking Coal & 28.20 & 29.50 & 0.97 \\
\hline \multirow[t]{2}{*}{16} & Coal Tar & 28.00 & 22.00 & 0.75 \\
\hline & (C) Gaseous & & & \\
\hline 17 & $\mathrm{CNG}$ & 48.00 & 15.30 & 0.99 \\
\hline
\end{tabular}

To set the local specific values of the FOC, Qu [27] suggests that the sector specific values of FOC for coal vary between $80 \%-95 \%$, which are smaller than the IPCC default value of $98 \%$. Equation (9) is the $\mathrm{CO}_{2}$ emission estimation (E) approach provided by IPCC [25], which includes main fuel combustion 
as listed in Table 1. China typically converts all its energy statistics into the metric tons of standard coal equivalent (TCE), a unit that bears little relation to the heating value of coals actually being used in China [28], whose HCF, CEF and FOC are given in the row $i=0$ in Table 1.

$$
E=\sum_{i=1}^{n_{1}} \tau \gamma_{i}\left(\alpha_{i} \beta_{i} A_{i} \times 10^{-3}-S_{i}\right)
$$

where,

$\circ \mathrm{E}$ is the $C \mathrm{O}_{2}$ emission, $10^{3} t$;

$\circ \tau=44 / 12$ is the molecular weight ratio of $\mathrm{CO}_{2}$ to $\mathrm{C}$ (Conversion between $\mathrm{C}$ and $\mathrm{CO}_{2}$ can be calculated using the relative atomic weights of the carbon and oxygen atoms $C=12, O=16$. The atomic weight of carbon is 12 and that of $\mathrm{CO}_{2}$ is $12+16+16=44$, i.e., one carbon and two oxygen atoms. To convert from $\mathrm{C}$ to $\mathrm{CO}_{2}$ thus requires multiplication by 44/12, or 3.67 [25].);

$\circ \gamma_{i}$ is the fraction of carbon oxidised $\left(i=1,2, \ldots, n_{1}\right), n_{1}=17$;

$\circ \alpha_{i}$ is the heat conversion factor, $T J / 10^{3} t$;

$\circ \beta_{i}$ is the carbon emission factor, which is considered as the carbon content per unit of energy for its close link between the carbon content and energy value of the fuel, $t C / T J$;

$\circ S_{i}$ is the non-energy use, $10^{3} t$;

$\circ A_{i}$ is the apparent consumption, $t$;

$$
A_{i}=O_{i}+I_{i}-X_{i}-B_{i}-R_{i}
$$

$\circ O_{i}$ is the energy production, $t$;

$\circ I_{i}$ is the import energy, $t$;

$\circ X_{i}$ is the export energy, $t$;

$\circ B_{i}$ is the international bunkers, $t$;

$\circ R_{i}$ is the stock change, $t$;

Subject to the requirements outlined above, to ensure the comparability of country inventories, the IPCC approach to the calculation of emission encourages the use of fuel statistics collected by an officially recognised national body. However, practically, the IPCC approach can hardly be utilised for the $\mathrm{CO}_{2}$ emission estimation with two main reasons. Firstly, recent satellite data has shown that the drop in coal consumption is probably unrealistic and the coal consumption data should not be used [2,3]. Secondly, the $\mathrm{CO}_{2}$ emissions data by fuel combustion and each local province are not directly available.

To handle this problem, Chen et al. have proposed a GDP approach [12], which employs the GDP data to estimate the $\mathrm{CO}_{2}$ emission. Empirical studies indicate that the GDP approach provides a reasonable $\mathrm{CO}_{2}$ emission result that is consistent with other researchers' works [29,30]. As given in Equation (11), the TCE/GDP energy statistics of provincial data are listed in Table 2. $\kappa_{j}$ is the $\mathrm{CO}_{2}$ emission 
estimation of each province $j$, as expressed in Equation (12), $j=1,2, \ldots n_{2}, n_{2}=31$, which is also shown in Figure 4.

Table 2. China energy statistical data [31].

\begin{tabular}{|c|c|c|c|c|c|c|c|}
\hline$j$ & Province & $e_{j}$ & $g_{j}$ & $f_{j}$ & $\hat{\boldsymbol{A}}_{j}$ & $\hat{B}_{j}$ & $\kappa_{j}$ \\
\hline 1 & Beijing & 0.662 & 104880300 & 719.61 & 69430758.6 & 476.38182 & $165,916.0$ \\
\hline 2 & Tianjing & 0.947 & 63543800 & 910.42 & 60175978.6 & 862.16774 & $143,800.2$ \\
\hline 3 & Hebei & 1.727 & 161886100 & 1492.81 & 279577294.7 & 2578.08287 & $668,095.1$ \\
\hline 4 & Shanxi & 2.554 & 69387300 & 2288.87 & 177215164.2 & 5845.77398 & $423,484.4$ \\
\hline 5 & Neimenggu & 2.159 & 77618000 & 1887.32 & 167577262 & 4074.72388 & $400,453.0$ \\
\hline 6 & Liaoning & 1.617 & 134615700 & 1223.81 & 217673586.9 & 1978.90077 & $520,166.2$ \\
\hline 7 & Jiling & 1.444 & 64240600 & 885.93 & 92763426.4 & 1279.28292 & $221,673.2$ \\
\hline 8 & Heilongjiang & 1.290 & 83100000 & 865.90 & 107199000 & 1117.011 & $256,169.3$ \\
\hline 9 & Shanghai & 0.801 & 136981500 & 884.13 & 109722181.5 & 708.18813 & $262,198.9$ \\
\hline 10 & Jiangshu & 0.803 & 303126100 & 1149.44 & 243410258.3 & 923.00032 & $581,668.1$ \\
\hline 11 & Zhejiang & 0.782 & 214869200 & 1202.08 & 168027714.4 & 940.02656 & $401,529.4$ \\
\hline 12 & Anhui & 1.075 & 88741700 & 1106.81 & 95397327.5 & 1189.82075 & $227,967.3$ \\
\hline 13 & Fujian & 0.843 & 108231100 & 1098.56 & 91238817.3 & 926.08608 & $218,029.9$ \\
\hline 14 & Jiangxi & 0.928 & 64803300 & 942.16 & 60137462.4 & 874.32448 & $143,708.2$ \\
\hline 15 & Shandong & 1.100 & 310720600 & 1001.08 & 341792660 & 1101.188 & $816,768.7$ \\
\hline 16 & Henan & 1.219 & 184077800 & 1266.23 & 224390838.2 & 1543.53437 & $536,218.2$ \\
\hline 17 & Hubei & 1.314 & 113303800 & 1103.90 & 148881193.2 & 1450.5246 & $355,775.7$ \\
\hline 18 & Hunan & 1.225 & 111566400 & 975.49 & 136668840 & 1194.97525 & $326,592.3$ \\
\hline 19 & Guangdong & 0.715 & 356964600 & 1085.49 & 255229689 & 776.12535 & $609,912.5$ \\
\hline 20 & Guangxi & 1.106 & 71715800 & 1254.15 & 79317674.8 & 1387.0899 & $189,542.4$ \\
\hline 21 & Hainan & 0.875 & 14592300 & 979.24 & 12768262.5 & 856.835 & $30,511.8$ \\
\hline 22 & Chongqing & 1.267 & 50966600 & 1090.19 & 64574682.2 & 1381.27073 & $154,311.7$ \\
\hline 23 & Sichuan & 1.381 & 125062500 & 1156.37 & 172711312.5 & 1596.94697 & $412,721.6$ \\
\hline 24 & Guizhou & 2.875 & 33334000 & 2452.21 & 95835250 & 7050.10375 & $229,014.0$ \\
\hline 25 & Yunnan & 1.562 & 57001000 & 1654.94 & 89035562 & 2585.01628 & $212,764.9$ \\
\hline 26 & Xizang & 0 & 3959100 & 0 & 0 & 0 & 0 \\
\hline 27 & Shaanxi & 1.281 & 68513200 & 1256.02 & 87765409.2 & 1608.96162 & $209,729.7$ \\
\hline 28 & Gansu & 2.013 & 31761100 & 2539.00 & 63935094.3 & 5111.007 & $152,783.4$ \\
\hline 29 & Qinhai & 2.935 & 9615300 & 4061.64 & 28220905.5 & 11920.9134 & $67,438.7$ \\
\hline 30 & Ningxia & 3.686 & 10985100 & 5084.09 & 40491078.6 & 18739.95574 & $96,760.5$ \\
\hline \multirow[t]{2}{*}{31} & Xingjiang & 1.963 & 42034100 & 1331.24 & 82512938.3 & 2613.22412 & $197,178.1$ \\
\hline & $\hat{E}$ & & & & & & $9,232,883.4$ \\
\hline
\end{tabular}


Figure 4. $\mathrm{CO}_{2}$ emission estimation of province $j$.

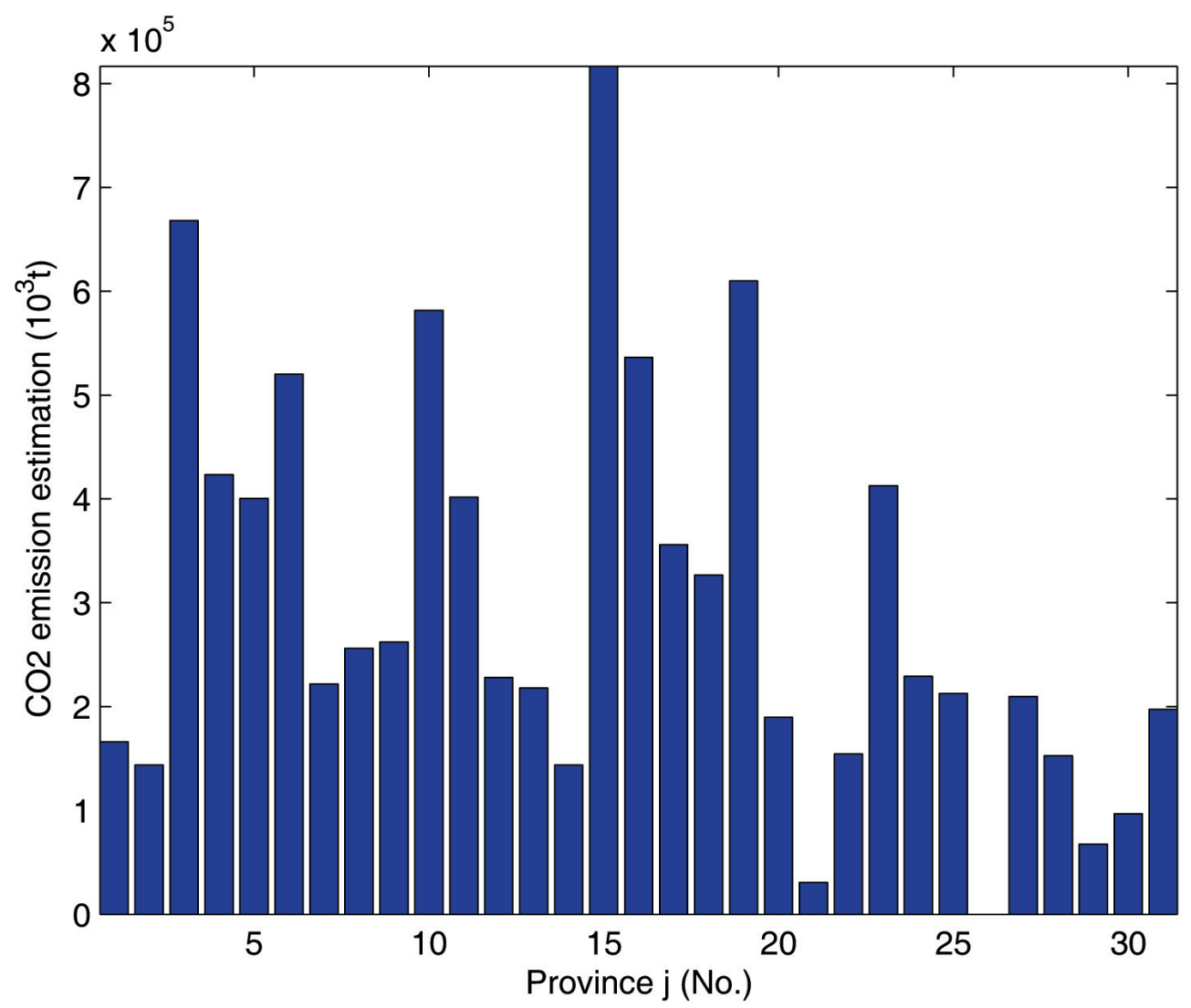

The energy consumption data constructed from the GDP $g_{j}$ and its related energy consumption $e_{j}$ and electricity consumption $f_{j}$ of the province $j$ can be collected and are officially provided by the "Chinese Energy Statistical Yearbook" [31]. $\hat{A}_{j}$ is the $\mathrm{CO}_{2}$ estimation of the equivalent energy consumption of province $j, \hat{B}_{j}$ is the $C_{2}$ estimation of the equivalent electricity consumption, as given in Equations (13) and (14).

$$
\begin{gathered}
\hat{E}=\sum_{j=1}^{n_{2}} \kappa_{j} \\
\kappa_{j}=\tau \gamma_{0} \alpha_{0} \beta_{0}\left(\hat{A}_{j}+\nu_{0} \hat{B}_{j}\right) \times 10^{-3} \\
\hat{A}_{j}=e_{j} g_{j} \\
\hat{B}_{j}=f_{j} g_{j}
\end{gathered}
$$

where,

$\circ \hat{E}$ is the total TCE $\mathrm{CO}_{2}$ emission estimation of the provincial rural areas, $10^{3} t$;

$\circ \kappa_{j}$ is the $\mathrm{CO}_{2}$ emission estimation of province $j$ by GDP, as listed in Table 2, $10^{3} t$;

$\circ g_{j}$ is the gross domestic product (GDP) of province $j, 10^{4} C N Y$; 
$\circ e_{j}$ is the TCE energy consumption per GDP unit of province $j$, TCE $/ 10^{4} C N Y$;

$\circ f_{j}$ is the electricity consumption per GDP unit of province $j, k W h / 10^{4} C N Y$;

$\circ \nu_{0}$ is the ratio of electricity to TCE, which is 0.01182 in this case (Electricity is converted to TCE by the equation $104 k W h=1.229 \mathrm{TCE}$, that is, $\nu_{0}=1.229 / 104=0.01182$ [31]);

$\circ \tau, \gamma_{0}, \alpha_{0}$ and $\beta_{0}$ are the molecular weight ratio of $\mathrm{CO}_{2}$ to $C$, the TCE fraction of carbon oxidised, the TCE heat conversion factor and the TCE carbon emission factor, as given in Table $1, j=1, \ldots, n_{2}$.

\section{Multi-State Dynamic Behaviours Modelling}

As demonstrated in Figure 5, the multi-state system (MSS) is expressed by a power function $\left(y=x^{a}\right)$, in which $a$ is the multi-state factor (MSF) that can provide different multi-state combinations by different $a$ 's values. Figure 5(a) and Figure 5(b) represent an increase $(a>0)$ and a decrease $(a<0)$ in economic activities, respectively. The power function MSS representation can provide a qualitative tool to perform a functional distance related interactive analysis and can be utilised as a fitness function for the AFSAVP optimisation process.

Figure 5. Multi-state representation via power functions.

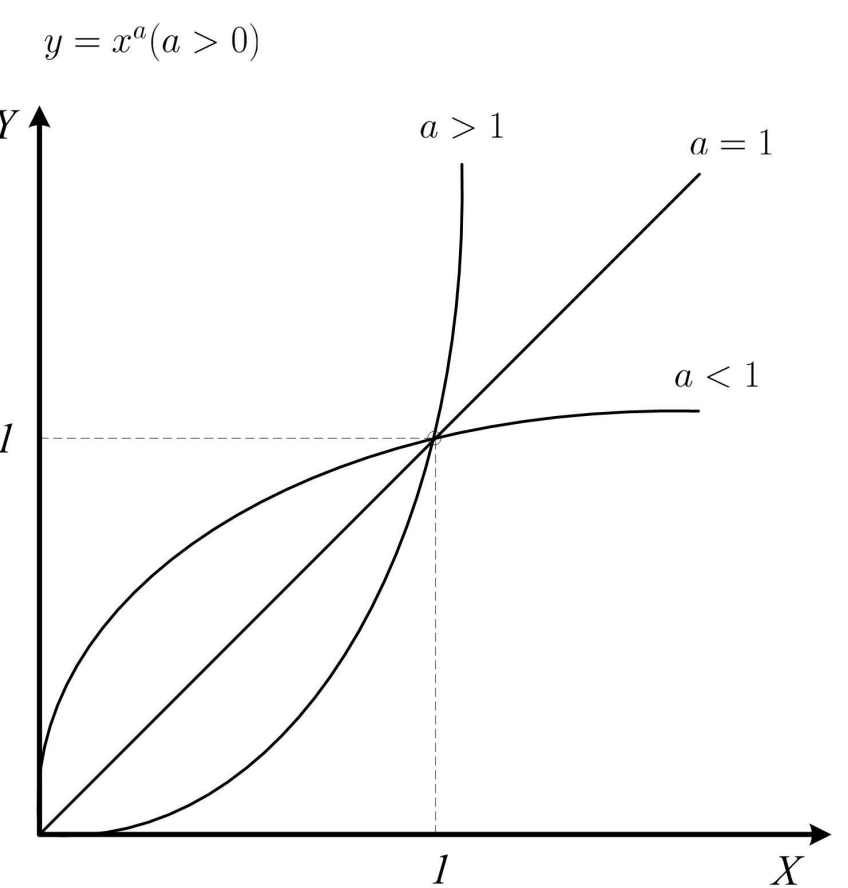

(a) $(a>0)$

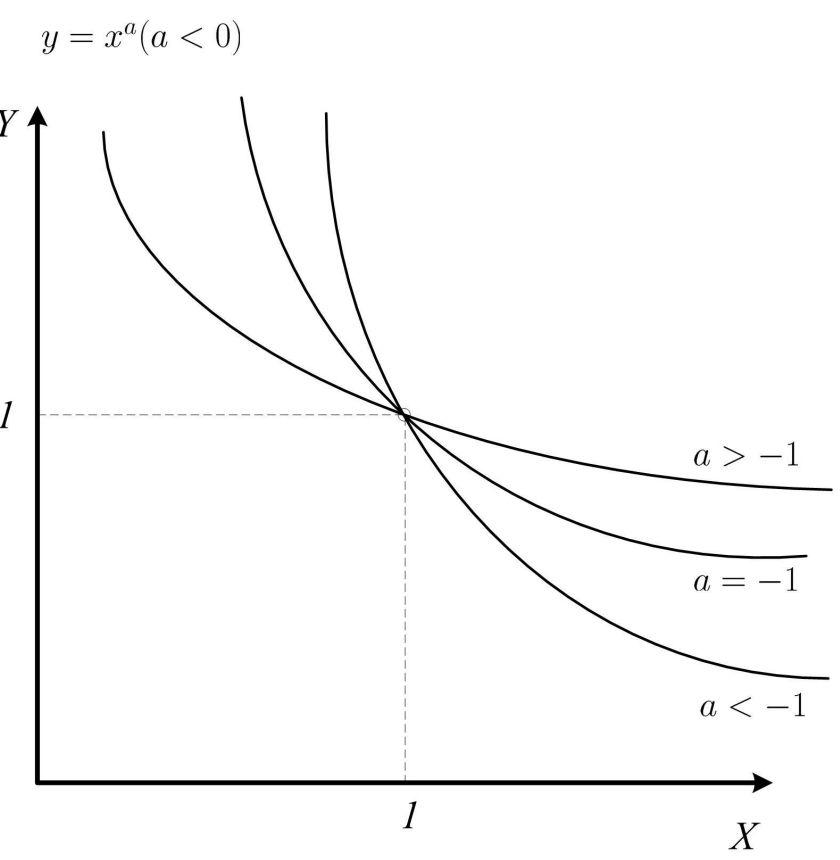

(b) $(a<0)$

In this paper, the statistics data of 31 provinces are adopted from China Statistical Yearbook 2009 [32]. In order to estimate the rural-urban(R-U) spatial interactions, a functional region affecting index $(\Theta)$ with a "law-of-gravity" interpretation [12] can be characterised as Equation (15) by using the basic form of a Cobb-Douglas (C-D) production function [33], which can provide a qualitative tool to perform a distance-related interactive analysis and can be utilised as the fitness function for AFSAVP optimisation. 
A case in Figure 6 shows the Sichuan province location and its functional distance measurement. Taking Sichuang province (province $j=23$ ) as an example, $O$ is the capital of China (Beijing), $r_{1}$ and $r_{2}$ are the shortest and longest radii (the distances $r_{1}$ and $r_{2}$ are provided by the GIS system China Map, http://www.51ditu.com/) from $O$ to Sichuan, $A$ and $B$ are the closest and farthest locating points of Sichuan to Beijing.

$$
\Theta=\sum_{j=1}^{n_{2}}\left(\alpha_{j} \frac{y_{j}}{\kappa_{j}} \frac{z_{j}}{x_{j} r_{j}^{\beta}+\epsilon}\right)^{\eta_{j}}
$$

where,

$\circ \Theta$ is the functional region affecting index;

$\circ x_{j}$ is the number of enterprises in the province $j, n_{2}$ is the number of the provinces;

$\circ y_{j}$ is the total profits of province $j, 10^{4} C N Y$;

$\circ z_{j}$ is the non-agricultural employment of province $j, 10^{4}$ persons;

○ $\alpha_{j}=\alpha_{1 j} / \alpha_{0 j}$ is the population effect coefficient of province $j, \alpha_{1 j}$ is the local non-agricultural population, $\alpha_{0 j}$ is the population of province $j, 10^{4}$ persons;

$\circ \kappa_{j}$ is the $\mathrm{CO}_{2}$ emission of province $j$, as listed in Table 2;

$\circ \eta_{j}$ is the multi-state factor of province $j, \eta_{j} \in[-1,1]$, as defined in Equation (16), which is the normalised $g_{j}, g_{\min }$ and $g_{\max }$ are the min and $\max$ values of $g_{j}$. According to the historical data and statistics, $\eta_{j}$ is utilised to describe the MSS weighted behaviour of the uncertainty analysis;

$$
\eta_{j}=2\left(\frac{g_{j}-g_{\min }}{g_{\max }-g_{\min }}\right)-1
$$

$\circ \beta$ is the factor of the functional distance $r_{j}, \beta \in[0.5,3]$;

$\circ \epsilon$ is the floating point relative accuracy, which prevents the singularity in case of the $r_{j}^{\beta}$ is approaching to 0 and $\Theta$ is approaching to $\infty$, numerically;

o $r_{j}$ is the mean value of point-to-point distance from the point $O$ to each province $j$, as defined in Equation (17), kilometre $(\mathrm{km})$.

$$
r_{j}=\frac{r_{j 1}+r_{j 2}}{2}
$$


Figure 6. Functional distance measurement of Sichuan province.

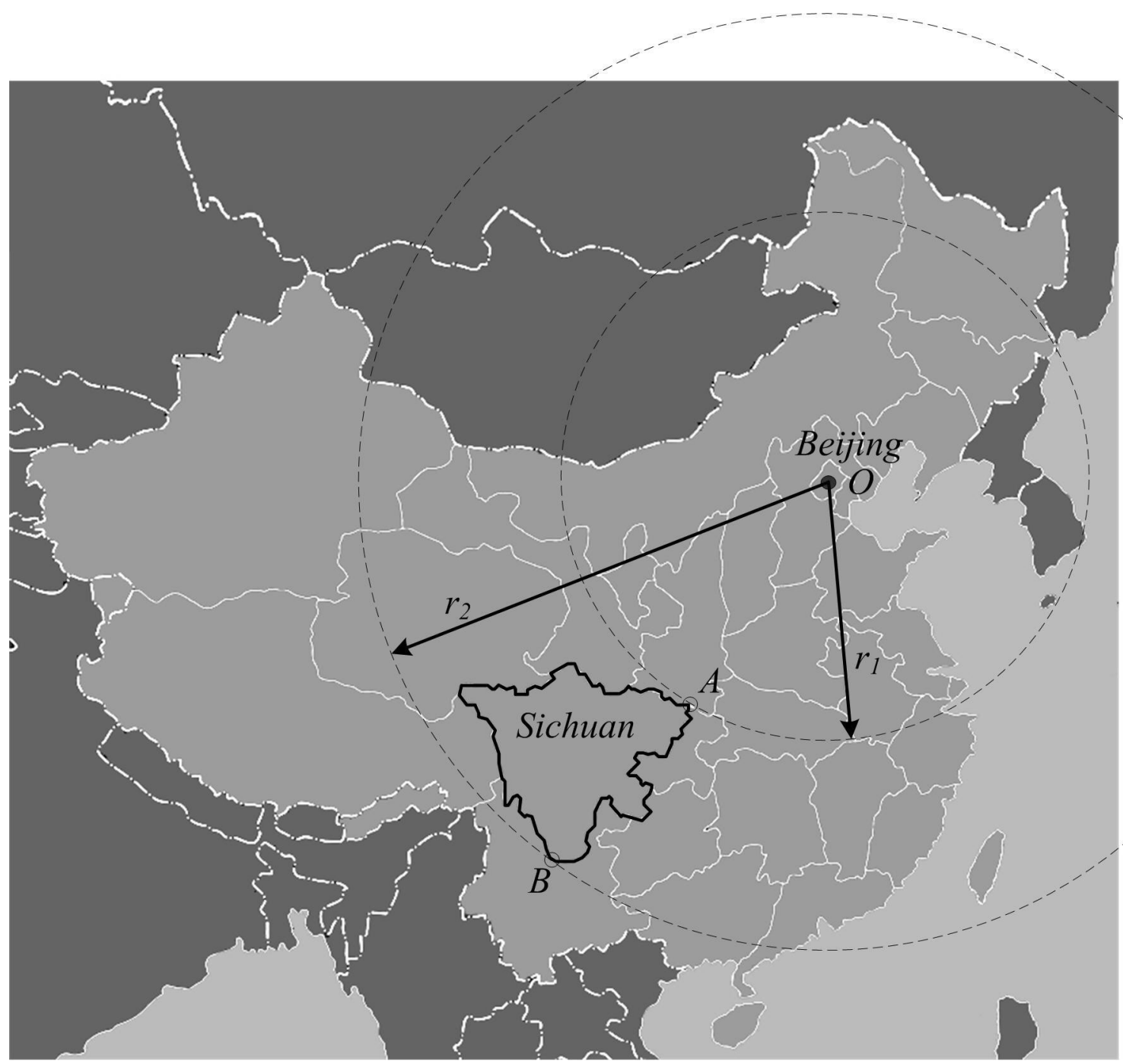

\section{Fitness Function Definition}

In order to evaluate the dynamic behaviour related to the functional distance, the $\mathrm{CO}_{2}$ emission and population in the provincial economic production, the $\Theta$ feature is utilised as the fitness function defined in Equation (18) by the form of Equation (15), which is a cumulative measurement for the functional region and $\mathrm{CO}_{2}$ emission spatial determination of the agreement between the statistical data and the AFSAVP driven data pool. All the statistical data for the parameters of Equation (18) are listed in Table 3, and the data source is the "China Statistical Yearbook 2009" [32].

$$
\digamma(X, Y, Z)=\sum_{j=1}^{n_{2}}\left(\alpha_{j} \frac{y_{j}}{\kappa_{j}} \frac{z_{j}}{x_{j} r_{j}^{\beta}+\epsilon}\right)^{\eta_{j}}
$$


Table 3. Statistical data for each province [32].

\begin{tabular}{|c|c|c|c|c|c|c|c|c|}
\hline No. $j$ & Province & $r_{j 1}$ & $r_{j 2}$ & $\alpha_{0 j}$ & $\alpha_{1 j}$ & $\boldsymbol{\mu}_{x_{j}}$ & $\mu_{y_{j}}$ & $\mu_{z_{j}}$ \\
\hline 1 & Beijing & 0.00 & 129.00 & 1695 & 1439 & 7205 & 5570000 & 123.38 \\
\hline 0 & Tianjing & 49.45 & 168.99 & 1176 & 908 & 7950 & 7527900 & 133.12 \\
\hline 3 & Hebei & 30.96 & 442.47 & 6989 & 2928 & 12447 & 13698400 & 316.85 \\
\hline 4 & Shanxi & 162.97 & 781.31 & 3411 & 1539 & 4415 & 6342500 & 214.93 \\
\hline 5 & Neimenggu & 206.83 & 1617.23 & 2414 & 1248 & 3993 & 7714400 & 104.57 \\
\hline 6 & Liaoning & 228.33 & 789.91 & 4315 & 2591 & 21876 & 7815800 & 366.23 \\
\hline 7 & Jiling & 689.29 & 1280.97 & 2734 & 1455 & 5257 & 3962300 & 126.99 \\
\hline 8 & Heilongjiang & 884.94 & 1752.25 & 3825 & 2119 & 4392 & 15816900 & 155.99 \\
\hline 0 & Shanghai & 976.53 & 1091.77 & 1888 & 1673 & 18792 & & 304.01 \\
\hline 10 & Jiangshu & 542.23 & 1059.09 & 7677 & 4169 & 65495 & 39729300 & 1104.06 \\
\hline 11 & Zhejiang & 995.88 & 1434.05 & 5120 & 2949 & 58816 & 16342000 & 814.55 \\
\hline 12 & Anhui & 571.47 & 1153.69 & 6135 & 2485 & 11392 & 6067300 & 210.8 \\
\hline 13 & Fujian & 1276.24 & 1783.64 & 3604 & 1798 & 17212 & 8961100 & 380.06 \\
\hline 14 & Jiangxi & 1069.41 & 1689.04 & 4400 & 1820 & 7367 & 5079600 & 178.56 \\
\hline 15 & Shandong & 216.72 & 625.65 & 9417 & 4483 & 42629 & 39235600 & 912.7 \\
\hline 16 & Henan & 420.97 & 932.24 & 9429 & 3397 & 18700 & 22877800 & 417.36 \\
\hline 17 & & & & 5711 & 2581 & 12067 & 9090300 & \\
\hline 18 & Hunan & 1127.46 & 1718.28 & 6380 & 2689 & 12391 & 6635600 & 225.55 \\
\hline 19 & Guangdong & 1584.55 & 2230.41 & 9544 & 6048 & 52574 & 32726000 & 1493.38 \\
\hline 20 & Guangxi & 1548.86 & 2166.34 & 4816 & 1838 & 5427 & 400 & 114.6 \\
\hline 21 & Hainan & 2223.53 & 3046.98 & 854 & 410 & 548 & & 12.61 \\
\hline 22 & Chongqing & 1071.13 & 1511.45 & 2839 & 1419 & 6119 & 3086800 & 132.13 \\
\hline 23 & Sichuan & 1097.36 & 2011.97 & 8138 & 3044 & 13725 & 8445600 & 297.54 \\
\hline 24 & Guizhou & 1382.45 & 1984.45 & 3793 & 1104 & 2676 & 1818300 & 73.53 \\
\hline 25 & Yunnan & 1646.04 & 2522.81 & 4543 & 1499 & 3320 & 3101400 & 84.34 \\
\hline 26 & Xizang & 1812.45 & 3418.07 & 287 & 65 & 88 & 45000 & 1.79 \\
\hline 27 & Shaanxi & 443.33 & 1193.68 & 3762 & 1584 & 4025 & 10089900 & 131.83 \\
\hline 28 & Gansu & 764.54 & 2032.18 & 2628 & 845 & 1940 & 1094600 & 69.13 \\
\hline 29 & Qinhai & 1221.63 & 2406.28 & 554 & 227 & 515 & 1771700 & 17.42 \\
\hline 30 & Ningxia & 774.43 & 1068.55 & 618 & 278 & 901 & 391300 & 25.89 \\
\hline 31 & Xingjiang & 1677.43 & 3590.93 & 2131 & 845 & 1859 & 7795200 & 57.84 \\
\hline
\end{tabular}

with the following assumptions of uncertainties,

$\circ X=\left[x_{1}, x_{2}, \ldots, x_{j}, \ldots, x_{n_{2}}\right]$ is the vector of the enterprise number, $X \sim N\left(\mu_{X}, \sigma_{X}^{2}\right)$. Let $\mu_{X}=\left[\mu_{x_{1}}, \mu_{x_{2}}, \ldots, \mu_{x_{j}}, \ldots, \mu_{x_{n_{2}}}\right]$ and $\sigma_{X}=\left[\sigma_{x_{1}}, \sigma_{x_{2}}, \ldots, \sigma_{x_{j}}, \ldots, \sigma_{x_{n_{2}}}\right]$ be the mean and the standard deviation vectors of $X$, respectively, that is, $x_{j} \sim N\left(\mu_{x_{j}}, \sigma_{x_{j}}^{2}\right), \mu_{x_{j}}$ and $\sigma_{x_{j}}$ are the mean and the standard deviation of $x_{j}$; 
$\circ Y=\left[y_{1}, y_{2}, \ldots, y_{j}, \ldots, y_{n_{2}}\right]$ is the vector of the total profits, $Y \sim N\left(\mu_{Y}, \sigma_{Y}^{2}\right)$. Let $\mu_{Y}=\left[\mu_{y_{1}}\right.$, $\left.\mu_{y_{2}}, \ldots, \mu_{y_{j}}, \ldots, \mu_{y_{n_{2}}}\right]$ and $\sigma_{Y}=\left[\sigma_{y_{1}}, \sigma_{y_{2}}, \ldots, \sigma_{y_{j}}, \ldots, \sigma_{y_{n_{2}}}\right]$ be the mean and the standard deviation vectors of $Y$, respectively, such that $y_{j} \sim N\left(\mu_{y_{j}}, \sigma_{y_{j}}^{2}\right), \mu_{y_{j}}$ and $\sigma_{y_{j}}$ are the mean and the standard deviation of $y_{j}$;

$\circ Z=\left[z_{1}, z_{2}, \ldots, z_{j}, \ldots, z_{n_{2}}\right]$ is the vector of the non-agricultural employment, $Z \sim N\left(\mu_{Z}, \sigma_{Z}^{2}\right)$. Let $\mu_{Z}=\left[\mu_{z_{1}}, \mu_{z_{2}}, \ldots, \mu_{z_{j}}, \ldots, \mu_{z_{n_{2}}}\right]$ and $\sigma_{Z}=\left[\sigma_{z_{1}}, \sigma_{z_{2}}, \ldots, \sigma_{z_{j}}, \ldots, \sigma_{z_{n_{2}}}\right]$ be the mean and the standard deviation vectors of $Z$, respectively, such that $z_{j} \sim N\left(\mu_{z_{j}}, \sigma_{z_{j}}^{2}\right), \mu_{z_{j}}$ and $\sigma_{z_{j}}$ are the mean and the standard deviation of $z_{j}$;

$\circ \delta_{x_{j}}, \delta_{y_{j}}$ and $\delta_{z_{j}}$ are the coefficients of variation $(\mathrm{CV})$ of $x_{j}, y_{j}$ and $z_{j}$ respectively, with the definition in Equation (19) [34]. The rest parameters $\alpha_{j}, \beta, r_{j}, \kappa_{j}, \epsilon$ and $\eta_{j}$ are as discussed in Section 4;

$$
\delta_{j}=\frac{\sigma_{x_{j}}}{\mu_{x_{j}}}
$$

\section{Empirical Results and Discussions}

The empirical data analysis for the AFSAVP driven hybrid modelling of the dynamic behaviours are implemented by the SwarmFish [35] toolbox and the parameters of the AFSAVP calculation are stated in Table 4, in which the termination condition is 100,000 max generations, the coefficients of variation $\delta_{j}$ for all $x_{j}, y_{j}$ and $z_{j}$ are set to $15 \%$, the experiment number is 100 , the non-replaceable $P_{N}$ and replaceable population $P_{R}$ are 50 and 10, iterate step $\delta$ is 0.5 , visual $v$ is 10 , crowd $\eta$ is 0.618 , try number is 5 for each AF.

Table 4. Parameters for the AFSAVP simulations.

\begin{tabular}{lll}
\hline & max generations & 100,000 \\
& experiment number & 100 \\
& population & 60 \\
$P_{N}$ & non-replaceable population & 50 \\
$P_{R}$ & replaceable population & 10 \\
& $\mathrm{CV}\left(\delta_{j}\right)$ & $15 \%$ \\
$\delta$ & iterate step & 0.5 \\
$v$ & visual & 2.5 \\
$\eta$ & crowd & 0.618 \\
& try number & 5 \\
\hline
\end{tabular}

Figures 7-10 are the fitness plots for 100, 1000, 10,000 and 100,000 generations, whose "x-axis" is the evolution generations and "y-axis" is the fitness values. These figures demonstrate the short term $($ generation $=100)$, short-middle term $($ generation $=1000)$, middle term $($ generation $=10,000)$ and long term (generation $=100,000$ ) dynamic behaviours, in which the solid line, dotted line and dash-dot line 
are the "max", "min" and "mean" values of fitness evolution process. Different from the fitness shape for engineering applications, the fluctuations of the non-monotonic fitness curves indicate the dynamic behaviours of the provincial areas.

Figure 7. $\Theta$ fitness plot, 100 generations.

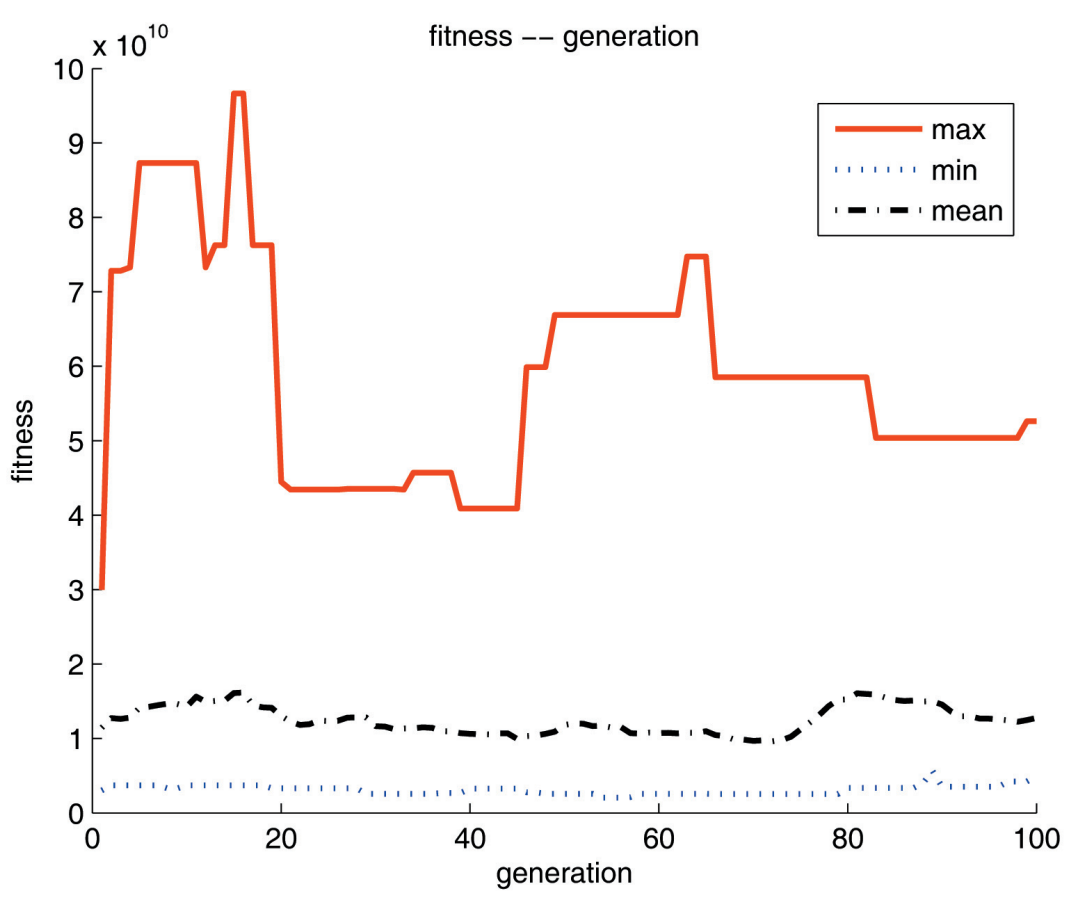

Figure 8. $\Theta$ fitness plot, 1000 generations.

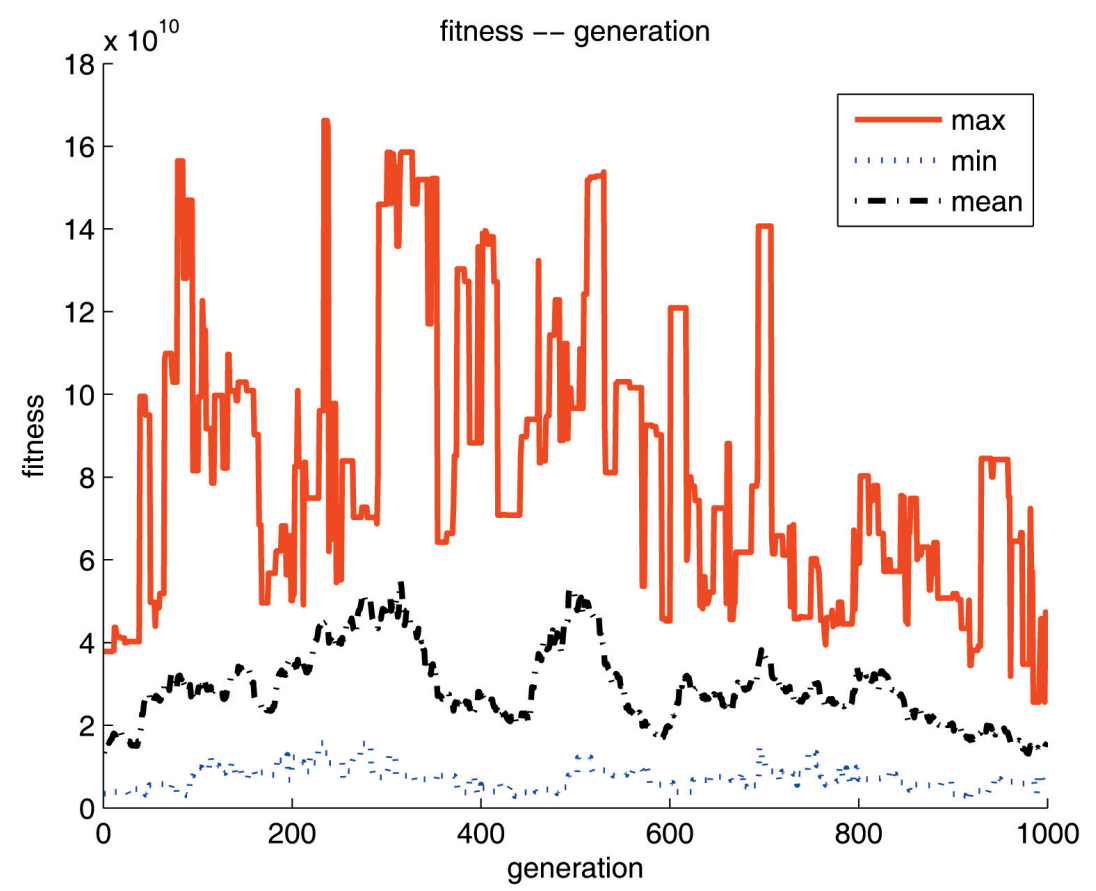


Figure 9. $\Theta$ fitness plot, 10,000 generations.

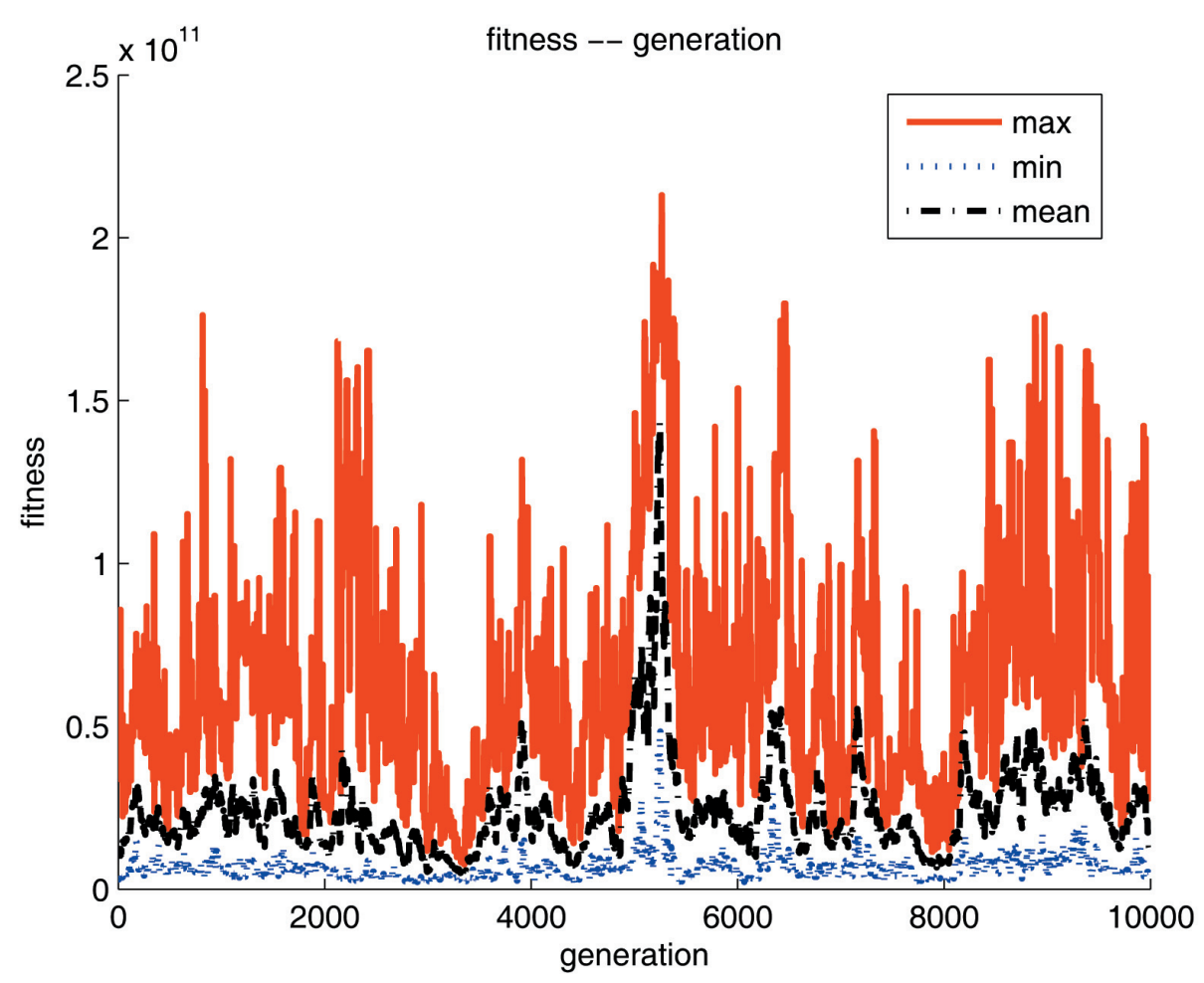

Figure 10. $\Theta$ fitness plot, 100,000 generations.

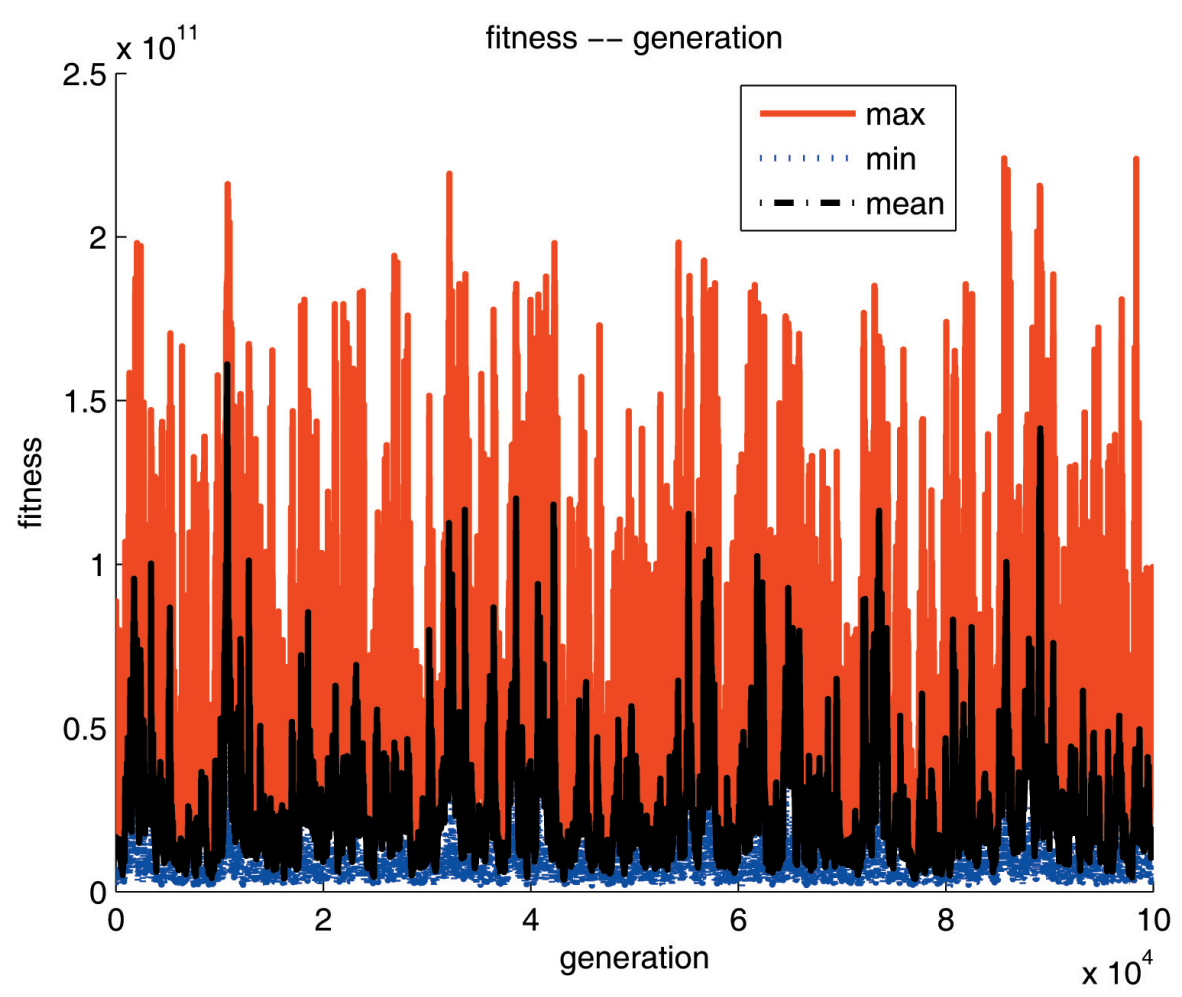

Figure 11 is the phase portrait of the "max" fitness at 100,000 generations, which demonstrate an isolated closed "limit cycle" phenomenon. This closed and isolated cycle indicates that the limiting 
nature of motions of the provincial dynamic system is in an overall stable state with limit active trajectories, depending on the motion patterns and evolutionary uncertainties.

Figure 11. Fitness phase portrait of the dynamic behaviours, 100,000 generations.

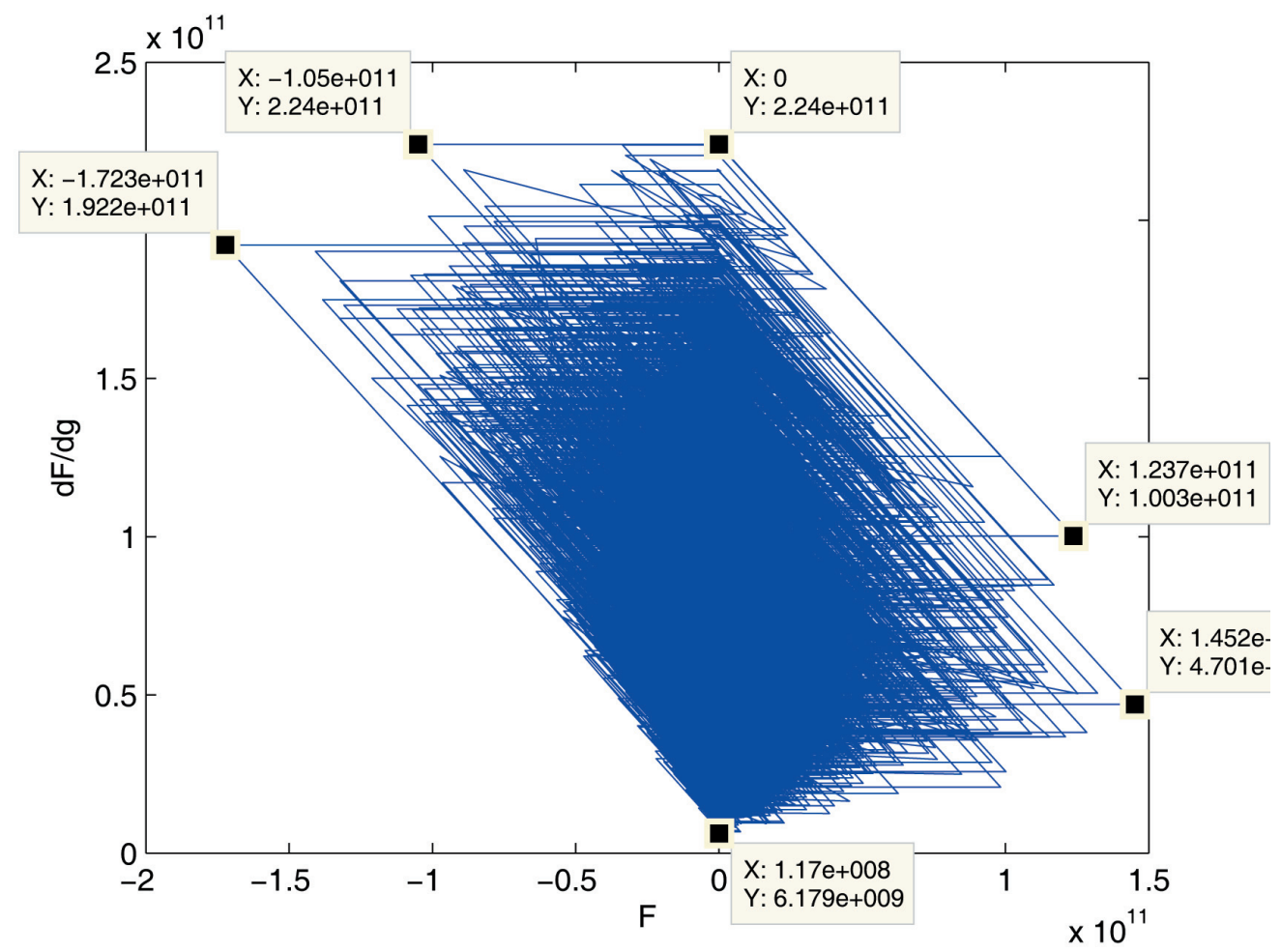

Table 5 states one of the set of estimation $\hat{X}=\left[\hat{x}_{1}, \hat{x}_{2}, \ldots, \hat{x}_{j}, \ldots, \hat{x}_{n_{2}}\right], \hat{Y}=\left[\hat{y}_{1}, \hat{y}_{2}, \ldots, \hat{y}_{j}, \ldots, \hat{y}_{n_{2}}\right]$ and $\hat{Z}=\left[\hat{z}_{1}, \hat{z}_{2}, \ldots, \hat{z}_{j}, \ldots, \hat{z}_{n_{2}}\right]$ for each province. Compared with the year book data $\mu_{x_{j}}, \mu_{y_{j}}$ and $\mu_{z_{j}}$ in Table 3, the negative percentage errors of $\Delta x_{j}(\%), \Delta y_{j}(\%)$ and $\Delta z_{j}(\%)$ indicate that the scale of the non-agricultural activities in the rural areas are in a decreasing trend, which matches the practical situation, that is, the rural areas of provinces are designed as the agriculture oriented functional regions administratively [32].

Table 5. An estimation $\hat{X}, \hat{Y}$ and $\hat{Z}$ optimised by the AFSAVP.

\begin{tabular}{llllllll}
\hline No. $j$ & Province & $\hat{\boldsymbol{x}}_{\boldsymbol{j}}$ & $\boldsymbol{\Delta} \boldsymbol{x}_{\boldsymbol{j}}(\boldsymbol{\%})$ & $\hat{\boldsymbol{y}}_{\boldsymbol{j}}$ & $\boldsymbol{\Delta} \boldsymbol{y}_{\boldsymbol{j}}(\%)$ & $\hat{\boldsymbol{z}}_{\boldsymbol{j}}$ & $\boldsymbol{\Delta} \boldsymbol{z}_{\boldsymbol{j}}(\%)$ \\
\hline 1 & Beijing & 2103.37 & -70.81 & 5259913.76 & -5.57 & 121.52 & -1.50 \\
2 & Tianjing & 7162.66 & -9.90 & 3875238.80 & -48.52 & 55.39 & -58.39 \\
3 & Hebei & 5471.55 & -56.04 & 3607953.26 & -73.66 & 94.19 & -70.27 \\
4 & Shanxi & 2828.75 & -35.93 & 1177466.56 & -81.44 & 64.13 & -70.16 \\
5 & Neimenggu & 671.11 & -83.19 & 4232075.41 & -45.14 & 31.17 & -70.19 \\
6 & Liaoning & 5099.33 & -76.69 & 5457102.47 & -30.18 & 102.12 & -72.12 \\
7 & Jiling & 3598.66 & -31.55 & 1516642.78 & -61.72 & 19.86 & -84.36 \\
8 & Heilongjiang & 2098.07 & -52.23 & 15558105.89 & -1.64 & 97.39 & -37.56 \\
\hline
\end{tabular}


Table 5. Cont.

\begin{tabular}{llllllll}
\hline No. $j$ & Province & $\hat{\boldsymbol{x}}_{\boldsymbol{j}}$ & $\boldsymbol{\Delta} \boldsymbol{x}_{\boldsymbol{j}}(\boldsymbol{\%})$ & $\hat{\boldsymbol{y}}_{\boldsymbol{j}}$ & $\boldsymbol{\Delta} \boldsymbol{y}_{\boldsymbol{j}}(\boldsymbol{\%})$ & $\hat{\boldsymbol{z}}_{\boldsymbol{j}}$ & $\boldsymbol{\Delta}_{\boldsymbol{j}}(\boldsymbol{\%})$ \\
\hline 9 & Shanghai & 13194.87 & -29.78 & 2140995.88 & -77.86 & 177.82 & -41.51 \\
10 & Jiangshu & 56854.80 & -13.19 & 23504968.27 & -40.84 & 603.88 & -45.30 \\
11 & Zejiang & 20379.23 & -65.35 & 7582321.11 & -53.60 & 492.79 & -39.50 \\
12 & Anhui & 9517.09 & -16.46 & 1358894.06 & -77.60 & 90.46 & -57.09 \\
13 & Fujian & 16657.98 & -3.22 & 7250945.22 & -19.08 & 210.31 & -44.66 \\
14 & Jiangxi & 5670.41 & -23.03 & 835757.42 & -83.55 & 119.53 & -33.06 \\
15 & Shandong & 28488.65 & -33.17 & 30320955.80 & -22.72 & 519.93 & -43.03 \\
16 & Henan & 14565.92 & -22.11 & 18769763.12 & -17.96 & 353.91 & -15.20 \\
17 & Hubei & 2328.84 & -80.70 & 4579725.46 & -49.62 & 154.24 & -34.62 \\
18 & Hunan & 5928.32 & -52.16 & 2768458.57 & -58.28 & 75.74 & -66.42 \\
19 & Guangdong & 15277.99 & -70.94 & 17910952.88 & -45.27 & 1449.28 & -2.95 \\
20 & Guangxi & 3994.28 & -26.39 & 1908639.57 & -17.42 & 105.45 & -7.98 \\
21 & Hainan & 208.35 & -61.98 & 609757.68 & -24.48 & 6.32 & -49.91 \\
22 & Chongqing & 4728.64 & -22.72 & 1044767.55 & -66.15 & 29.81 & -77.44 \\
23 & Sichuan & 3303.15 & -75.93 & 4154033.67 & -50.81 & 201.85 & -32.16 \\
24 & Guizhou & 1815.92 & -32.14 & 1590913.14 & -12.51 & 36.29 & -50.64 \\
25 & Yunnan & 2506.39 & -24.51 & 841518.18 & -72.87 & 52.04 & -38.29 \\
26 & Xizang & 17.85 & -79.72 & 10045.12 & -77.68 & 0.98 & -45.02 \\
27 & Shaanxi & 972.27 & -75.84 & 2669041.76 & -73.55 & 62.65 & -52.47 \\
28 & Gansu & 380.545 & -80.38 & 1003010.38 & -8.36 & 13.59 & -80.34 \\
29 & Qinhai & 119.59 & -76.78 & 546449.00 & -69.16 & 8.28 & -52.45 \\
30 & Ningxia & 638.53 & -29.13 & 302537.17 & -22.68 & 9.70 & -62.52 \\
31 & Xingjiang & 1448.19 & -22.09 & 1602668.49 & -79.44 & 16.49 & -71.49 \\
\hline & & & & & & & \\
12 & & & &
\end{tabular}

\section{Conclusions and Future Work}

In recent years, the quantitative analysis is widely utilised to assist the functional region planning decisions, which tries to take good advantage of the available statistical data. This paper provides an evolutionary alternative of dynamic behaviour modelling for functional region with distance factor and $\mathrm{CO}_{2}$ emission factor. In this paper, the AFSAVP is firstly introduced, then the GDP-based TCE approach for the $\mathrm{CO}_{2}$ emission estimation is discussed. For the hybrid modelling of provincial regions, the $\Theta$ factor is proposed to describe the interaction of the production inputs and outputs with the source data uncertainties, which indicates a sort of distance-based relationship between a $\Theta$ combination of the $X$, $Y$ and $Z$ inputs and the possible maximum output under current productive capability, in which the experience of a policy-maker can be incorporated in a natural or artificial way. It is clear that the $\mathrm{CO}_{2}$ emission is related to the complicated dynamic behaviours of the functional region. The GDP/TCE 
approach to the $\mathrm{CO}_{2}$ emission estimation is a practical way to deal with the lack of direct fossil fuel data source.

This paper's results are consistent with the actual behaviours of the functional regions, which suggests some interesting issues for further investigation on the real-time public sector policy making, in which the consumer price index (CPI) will be one of the dynamic decision criteria for the further reliability analysis of a multi-state $\Theta$ modelling or the analysis of the regional system maintenance and sustainability.

\section{Notations}

$\begin{array}{ll}\text { AFSAVP } & \text { artificial fish swarm algorithm with variable population size } \\ \mathrm{CO} & \text { carbon monoxide } \\ \mathrm{CO}_{2} & \text { carbon dioxide } \\ \mathrm{CH}_{4} & \text { methane } \\ \mathrm{CNY} & \text { Chinese yuan (renminbi) } \\ \digamma & \text { fitness function } \\ \text { GDP } & \text { gross domestic product } \\ \text { GA } & \text { genetic algorithms } \\ k W h & \text { kilowatt hour } \\ \mathrm{NO}_{x} & \text { nitrogen oxides } \\ \mathrm{SO}_{2} & \text { silicon dioxide } \\ \Theta & \text { functional region affecting index } \\ \mathrm{TCE} & \text { metric tons of standard coal equivalent }\end{array}$

\section{Acknowledgments}

The authors would like to acknowledge the partial supports provided by the National Natural Science Foundation of China (No. 61179059, 51105061 and 50905028), the Scientific Research Foundation for the Returned Overseas Chinese Scholars, the State Education Ministry No. 201294001 and the Program for New Century Excellent Talents in University (No. NCET-11-0063). The authors would also like to acknowledge Shaomin $\mathrm{Wu}$ (University of Kent) and Yong Ma (Heriot-Watt University) for their valuable comments on this paper.

\section{References}

1. Liu, J.; Diamond, J. China's environment in a globalizing world. Nature 2005, 435, 1179-1186.

2. Peters, G.; Weber, C.; Liu, J.R. Construction of Chinese Energy and Emissions Inventory; Report Numbers 4/2006, Norwegian University of Science and Technology (NTNU) Industrial Ecology Programme, 2006.

3. Akimoto, H.; Ohara, T.; Kurokawa, J.I.; Horiid, N. Verification of energy consumption in China during 1996-2003 by using satellite observational data. Atmos. Environ. 1999 , 40, 7663-7667.

4. Berling-Wolff, S.; Wu, J.G. Modeling urban landscape dynamics: A review. Ecol. Res. 2004, 19, 119-129. 
5. Nejadkoorki, F.; Nicholson, K.; Lake, I.; Davies, T. An approach for modelling $\mathrm{CO}_{2}$ emissions from road traffic in urban areas. Sci. Total Environ. 2008, 406, 269-278.

6. Weiss, M.; Neelis, M.; Blok, K.; Patel, M. Non-energy use of fossil fuels and resulting carbon dioxide emissions: Bottom-up estimates for the world as a whole and for major developing countries. Clim. Chang. 2009, 95, 369-394.

7. Bala, K. Computer modelling of the rural energy system and of $\mathrm{CO} 2$ emissions for Bangladesh. Energy 1997, 22, 999-1003.

8. Winter, G.; Périaux, J.; Galán, M.; Cuesta, P. Genetic Algorithms in Engineering and Computer Science; John Wiley \& Sons: Hoboken, NJ, USA, 1996.

9. Alexouda, G.; Paparrizos, K. A genetic algorithm approach to the product line design problem using the seller's return criterion: an extensive comparative computational study. Eur. J. Oper. Res. 2001, 134, 165-178.

10. Kuo, R.J. A sales forecasting system based on fuzzy neural network with initial weights generated by genetic algorithm. Eur. J. Oper. Res. 2001, 129, 496-517.

11. Sels, V.; Craeymeersch, K.; Vanhoucke, M. A hybrid single and dual population search procedure for the job shop scheduling problem. Eur. J. Oper. Res. 2001, 215, 512-523.

12. Chen, Y.; Wang, X.-Y.; Sha, Z.-J.; Wu, S.-M. Uncertainty analysis for multi-state weighted behaviours of rural area with carbon dioxide emission estimation. Appl. Soft Comput. 2012, 12, 2631-2637.

13. Chen, Y.; Wang, Z.-L.; Qiu, J.; Huang, H.-Z. Hybrid fuzzy skyhook surface control using multi-objective micro-genetic algorithm for semi-active vehicle suspension system ride comfort stability analysis. J. Dyn. Syst. Meas. Control 2012, 134, 041003.

14. Chen, Y.; Zhang, G.-F. Exchange rates determination based on genetic algorithms using mendel's principles: Investigation and estimation under uncertainty. Inf. Fusion 2012, doi:10.1016/j.inffus.2011.12.003.

15. Chen, Y.; Song, Z.-J. Spatial analysis for functional region of suburban-rural area using micro genetic algorithm with variable population size. Exp. Syst. Appl. 2012, 39, 6469-6475.

16. Chen, Y.; Ma, Y.; Lu, Z.;Peng, B.; Chen, Q. Quantitative analysis of terahertz spectra for illicit drugs using adaptive-range micro-genetic algorithm. J. Appl. Phys. 2011, 110, 044902.

17. Chen, Y.; Ma, Y.; Lu, Z.; Qiu, L.-X.; He, J. Terahertz spectroscopic uncertainty analysis for explosive mixture components determination using multi-objective micro genetic algorithm. $A d v$. Eng. Softw. 2011, 42, 649-659.

18. Chen, Y.; Ma, Y.; Lu, Z.; Xia, Z.-N.; Cheng, H. Chemical components determination via terahertz spectroscopic statistical analysis using micro genetic algorithm. Opt. Eng. 2011, 50, 034401.

19. Chen, Y. Dynamical Modelling of a Flexible Motorised Momentum Exchange Tether and Hybrid Fuzzy Sliding Mode Control for Spin-up; PhD Thesis, Mechanical Engineering Department, University of Glasgow, Glasgow, 2010.

20. Chen, Y.; Cartmell, M.P. Multi-objective Optimisation on Motorized Momentum Exchange Tether for Payload Orbital Transfer. In Proceedings of 2007 IEEE Congress on Evolutionary Computation (CEC), Singapore, 25-28 September 2007. 
21. Chen, Y.; Wang, Z.-L.; Liu, Yu; Zuo, M.-J.; Huang, H.-Z. Parameters Determination for Adaptive Bathtub-shaped Curve Using Artificial Fish Swarm Algorithm. In Proceedings of the 58th Annual Reliability and Maintainability Symposium, Reno, NV, USA, 23-26 January 2012.

22. Chen, Y.; Wang, Z.-L.; Qiu, J.; Zheng, B.; Huang, H.-Z. Adaptive Bathtub Hazard Rate Curve Modelling via Transformed Radial Basis Functions. In Proceedings of International Conference on Quality, Reliability, Risk, Maintenance, and Safety Engineering (ICQR2MSE 2011, IEEE, Xi' an, China, 17-19 June 2011; pp. 110-114.

23. Li, X.L.; Shao, Z.J.; Qian, J.X. An optimizing method based on autonomous animate: Fish swarm algorithm. Syst. Eng. Theory Pract. 2002, 22, 32-38.

24. Shen, W.; Guo, X.P.; Wu, C.; Wu, D.S. Forecasting stock indices using radial basis function neural networks optimized by artificial fish swarm algorithm. Knowl.-Based Syst. 2011, 24, 378-385.

25. IPCC Revised 1996 IPCC Guidelines for National Greenhouse Gas Inventories: Reference Manual; NGGIP Publications: Kyoto, Japan, 1997; Volume 3.

26. Research Team of China Climate Change Country Study China Climate Change Country Study; Tsinghua University Press: Beijing, China, 2000.

27. Qu, J.S.; Wang, Q.; Chen, F.H.; Zeng, J.J.; Zhang, Z.Q.; Li, Y. Provincial analysis of carbon dioxide emission in China. Quat. Sci. 2010, 30, 466-472.

28. National Research Council, Chinese Academy of Sciences, Chinese Academy of Engineering, Cooperation in the Energy Futures of China and the United States; National Academy Press: Washington, D.C., USA, 2000.

29. Xu, S.Y. Initial Estimate of Carbon Dioxide Emission Benchmark of Chongqing; Master Thesis, Southwest University, Chongqing, China, 2010.

30. Geng, Y.-H.; Tian, M.-Z.; Zhu, Q.-A.; Zhang, J.-J.; Peng, C.-H. Quantification of provincial-level carbon emissions from energy consumption in China. Renew. Sustain. Energy Rev. 2011, 15 , 3658-3668.

31. National Bureau of Statistics of China (2009)- Chinese Energy Statistical Yearbook 2009; China Statistics Press: Beijing, China, 2009.

32. National Bureau of Statistics of China (2009)- China Statistical Yearbook 2009; China Statistics Press: Beijing, China, 2009.

33. Gujarati, D.N. Basic Econometrics(4e); McGraw-Hill Companies: New York, NY, USA, 2004.

34. Ott, R.L.; Longnecker, M. An Introduction to Statistical Methods and Data Analysis(5e); Duxbury: Pacific Grove, USA, 2001.

35. Chen, Y. SwarmFish-The Artificial Fish Swarm Algorithm. Available online: http://www.mathworks.com/matlabcentral/fileexchange/32022 (accessed 26 June 2011).

(c) 2013 by the authors; licensee MDPI, Basel, Switzerland. This article is an open access article distributed under the terms and conditions of the Creative Commons Attribution license (http://creativecommons.org/licenses/by/3.0/). 